\title{
Mesocolic hernia: unusual cause of intestinal obstruction in children
}

\section{Pranay Panigrahi ${ }^{1 *}$, Sarita Kumari ${ }^{2 *}$, Kanika Sharma ${ }^{1}$, Amrita Rath ${ }^{2}$, Deepak Kumar $^{1}$, Akash Mishra ${ }^{1}$, Sunil Kumar Gaur ${ }^{1}$, Shyamendra Pratap Sharma ${ }^{1}$ and Sarita Chowdhary ${ }^{1}$}

${ }^{1}$ Department of Paediatric Surgery, Institute of Medical Sciences, BHU, Uttar Pradesh, India

${ }^{2}$ Department of Anaesthesia, Institute of Medical Sciences, BHU, Uttar Pradesh, India

Keywords: Right Mesocolic hernia (RMH), Malrotation, internal hernia, Laparoscopy

\section{Corresponding author}

Sarita Chowdhary

Associate Professor, Department of

Paediatric Surgery, IMS BHU, India

E-mail: saritaimsbhu@yahoo.com

(*Both contributed as first author)

\begin{abstract}
Tntroduction: Internal hernia is considered under malrotation or defective rotation Lof mid-gut. Lack of fixation of the mesentery of the right or left colon may result in the formation of potential spaces. Entrapment of the mid-gut in these peritoneal sacs leads to a mesocolic hernia. Left mesocolic hernia occurs in $75 \%$ of internal hernias.
\end{abstract}

\begin{abstract}
Aim: This article describes six cases of right mesocolic hernia (RMH) collected retrospectively. Data of last decade analyzed which came out to be six cases of
\end{abstract} RMH in a total of 1988 cases.

Case details: Total of six cases of RMH were operated in tertiary pediatric surgical care. The median age was 7.75 years. One infant of 8 months age was also operated who presented with failure to thrive and malabsorption. The majority of cases were male children. Non-specific pain abdomen with vomiting was primarily found in all cases. Resuscitation was done in two cases who presented to emergency OPD with intestinal obstruction and dehydration. CECT abdomen revealed clusters of dilated edematous ileal loops with displaced cecum. Vascularity was delineated. Operated infant expired due to severe sepsis with multi-organ failure. Rest cases were doing well on follow-up.

Conclusion: Laparoscopic approach is better. Exploratory laparotomy could rule out associated malrotation which requires Ladd's procedure. CT abdomen is the gold standard. The right mesocolic hernia should be considered as a differential in all cases of malrotation of the mid-gut.
Internal hernias are protrusion of organs or bowel through an abnormal peritoneal sac or mesenteric aperture within the abdominal cavity. It could be congenital or acquired post surgery. (1) Congenital mesocolic hernias are due to lack of absorption of colon mesentery to parietal peritoneum. This free peritoneal reflection of colon creates potential space for hernia to occur. Preferring the term mesocolic over transmesenteric or paraduodenal for this type of hernia signifiesits embryological origin. (2) Left mesocolic hernia is more commonly reported as case reports. Even a rarer variety termed middle mesocolic hernia in the neonate is also described. (3) Congenital right mesocolic hernia $(\mathrm{RMH})$ is rarer and difficult to diagnose ascompared to left mesocolic hernia. Non-specific clinical features and rarity of this condition lead to a dilemma in diagnosis and are often thought to be psychologic. Preoperative sonography and 
abdominal CT scan are pivotal but rarely tend to pinpoint the defect. Surgical repair is the management of choice. Present article describe clinical features, imaging\& management of right mesocolic hernia in the pediatric population over the last decade from a single center.

\section{Case details}

This is a retrospective analysis of all cases admitted topediatric tertiary care with a provisional diagnosis of small bowel obstruction. Out of 1988 pediatric cases operated for small bowel obstruction or midgut volvulus over the last decade, six cases were found to be a right mesocolic hernia. Male child were more commonly affected. Median age was 7.75 years (Table 1$)$.

The youngest child was a male of age 8 months who presented with bilious vomiting occasionally and malabsorption syndrome. He had features of failure to thrive (FT'T) referred from the department of pediatrics. In two cases, the presentation was acute abdominal pain with non-bilious vomiting. Two out of six patients had features of intestinal obstruction with dehydration, obstipation and poor general condition. Non-specific pain abdomen without any relation to food intake was found in one male child of school-going age. Children who presented with feature of intestinal obstruction were assessed. On palpation, abdomen was tender and distended. Fluid \& electrolytes correction was primarily done before shifting for imaging. Rest cases who presented to outpatient department were advised for contrast enhanced tomography (CT). As all of four cases had got abdominal sonography or X-ray done elsewhere, CT scanning was preferred. Sonography of majority,showed ileal wall thickening and Doppler imaging of superior mesenteric vessels showed reversal of artery to vein relation. Sub-acute intestinal obstruction was reported in some cases. CECT abdomen revealed segment of dilated ileal segment (Fig. 1).

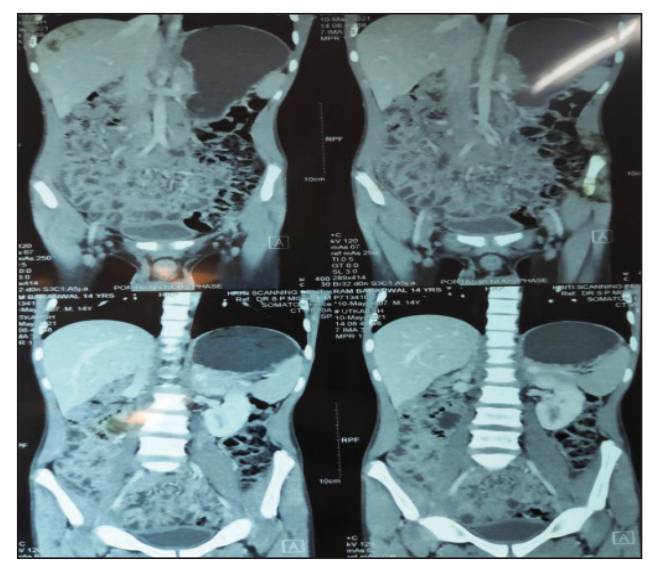

Fig. 1: Small Bowel Clusters in Right Iliac Fossa

Additionally vascularity if compromised was not clearly identified. Variability in position of caecum with small bowel loops cluster in right iliac fossa imaged on contrast CT films. Significant mesenteric lymph node mentioned in two cases. Blood tests suggested with a raised white cell count and low hemoglobin in three out of six cases. Plain abdominal X-ray film showed some fecal loading of the colon but was otherwise insignificant with absent free air under the diaphragm. After pre-operative optimization, cases of intestinal obstruction were operated by laparotomy. Supraumbilical transverse incision or midline incision involving umbilicus was used to assess abdominal cavity.

Table 1

\begin{tabular}{|c|c|c|c|c|c|l|l|l|}
\hline Patient & Sex & Age & Presentation & $\begin{array}{c}\text { General } \\
\text { condition }\end{array}$ & USG & \multicolumn{1}{|c|}{ CT scan finding } & $\begin{array}{c}\text { Preoperative } \\
\text { finding }\end{array}$ & \multicolumn{1}{|c|}{ Outcome } \\
\hline 1 & M & 6 & Vomiting & Stable & SAIO & $\begin{array}{l}\text { Dilated ileum, Vascularity } \\
\text { intact }\end{array}$ & RMH with repair & Satisfactory \\
\hline 2 & M & 14 & Obstruction & Unstable & SBO & $\begin{array}{l}\text { Ileum edematous, free fluid } \\
\text { peritoneum }\end{array}$ & $\begin{array}{l}\text { RMH with gangrene } \\
\text { ileal segment }\end{array}$ & Ileostomy \\
\hline 3 & F & 8 & Obstruction & Unstable & SAIO & Mid gut volvulus & RMH with RA & Satisfactory \\
\hline 4 & M & 7 & $\begin{array}{c}\text { Intermittent vomiting } \\
\text { with pain abdomen }\end{array}$ & Stable & $\begin{array}{c}\text { Midgut } \\
\text { volvulus }\end{array}$ & Enteritis, pulled-up Caecum & $\begin{array}{l}\text { DL - RMH with } \\
\text { reduction \& repair }\end{array}$ & Satisfactory \\
\hline 5 & M & 11 & $\begin{array}{c}\text { Abdominal pain with } \\
\text { melena }\end{array}$ & Stable & NAD & $\begin{array}{l}\text { Ileum loops in right iliac } \\
\text { region, significant MLN }\end{array}$ & $\begin{array}{l}\text { RMH with repair of } \\
\text { defect }\end{array}$ & Good \\
\hline 6 & M & $<1$ & FTT, ?MAS & Unstable & $\begin{array}{l}\text { SMA\&V } \\
\text { reversal }\end{array}$ & $\begin{array}{l}\text { Ileum on right side, } \\
\text { duodenum normal, caecum } \\
\text { in periumblical region }\end{array}$ & RMH with Meckel's & Expired \\
\hline
\end{tabular}



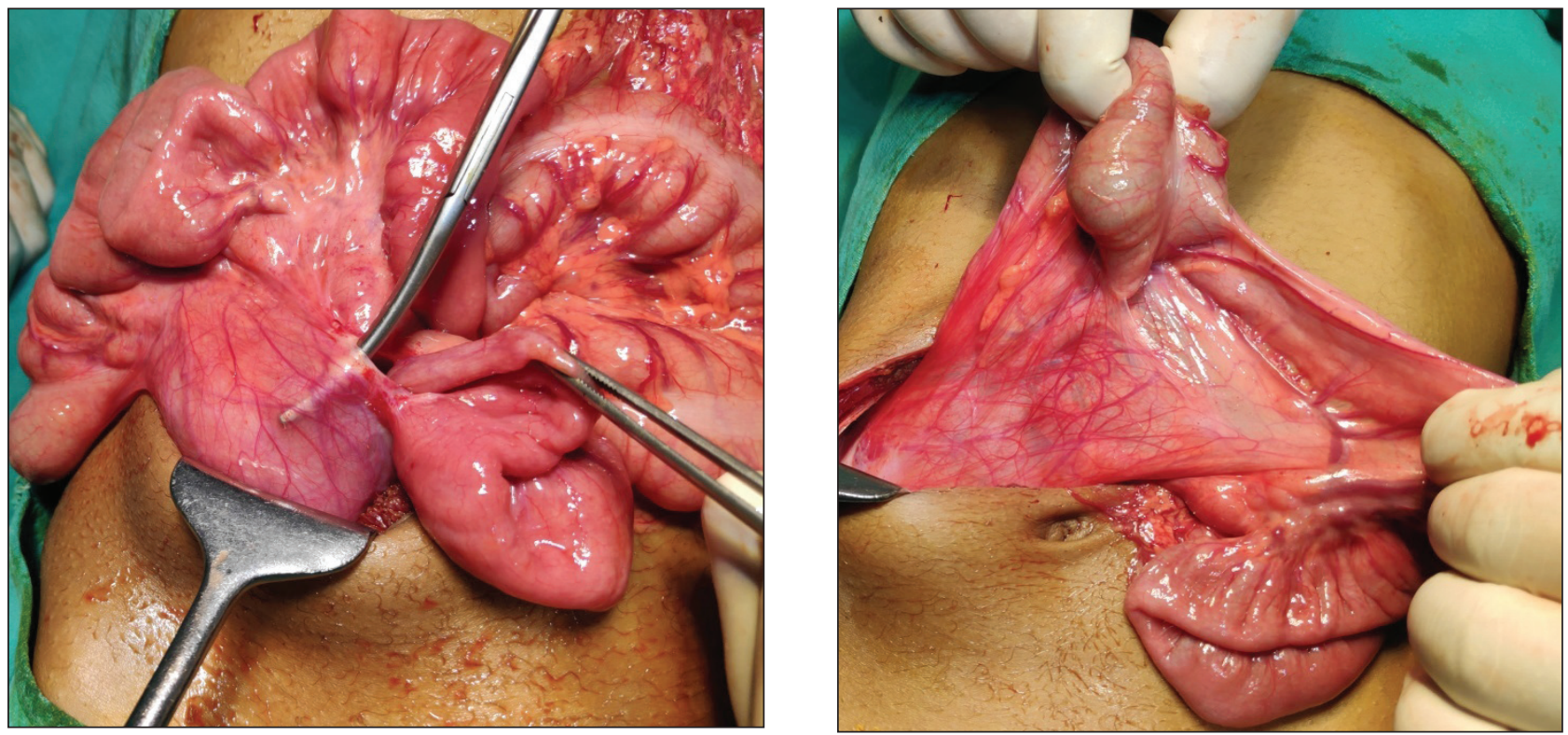

Fig. 2: Peritoneal SAC in Right Side with Small Bowel as Content

On inspection, small bowel segment was encased in a peritoneal sac present on right side of abdomen sparing proximal jejunal loops and small segment proximal to Ileocecal junction (Fig. 2). After dividing thick peritonealsac neck, hernial content reduced with intact vascularity. Gangrenous segment was resected and ileo-ileal anastomosis was done in some (Fig. 3).

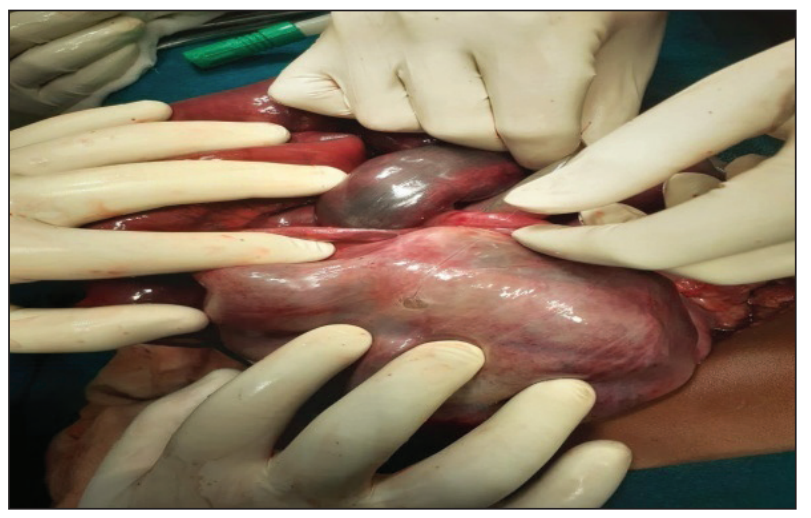

Fig. 3: Gangrenous Ileal Segment in Mesocolic SAC

Midgut volvulus in one case was addressed by performing Ladd's procedure with appendectomy. RMH sac was excised and defect of ascending mesocolon was repaired using 4-0 PGA. One case was approached via diagnostic laparoscopy, and then converted to open for reduction and repair of the defect. Three out of 6 cases required resection \& anastomosis of ileal segment. Oral liquid was allowed on third day post-operatively. Solid food was started from day 5 post operatively. All cases had satisfactory post-operative course except the infant. Operated infant developed sepsis on day $6^{\text {th }}$ of post-operative period and expired on day $12^{\text {th }}$ post-operatively with multi-organ dysfunction. Follow-up records couldn't be traced in two of cases. Rest cases were doing well.

\section{DISCUSSION}

Mesocolic hernias have variable incidence between $0.2 \%$ and $0.9 \%$, and $5.8 \%$ of all cases of small bowel obstruction were reported as mesocolic hernias. (4)(5). Around onefourth of all mesocolic hernias are right mesocolic hernia. $\mathrm{RMH}$ protrudes into the ascending mesocolon behind the superior mesenteric vessels. Fusion failure of ascending mesocolon with parietal peritoneum results in a potential sac like space. Entrapment of developing mid-gut in the sac leads to obstruction. (6) These hernias are common following reconstructive abdominal surgery, especially Roux-en-Y loop or liver transplant. (7) In general, internal hernia is three times more common in males than in females as noted in the present article. (8) Authors have noted RMH in infant very rare to be found as per other case reports from Asian perspective. (9) Majority of children with RMH had vomiting and chronic abdominal pain in the present series. (10). Many published literature mentioned asymptomatic 
child or mild symptoms in these cases. (6) Even many patients had been treated with anti-tubercular therapy due to dilemma in diagnosis. (11) Authors also suspected Koch's abdomen in two cases which turned to be mesocolic hernia in both. Malabsorption and failure to thrive in infants due to malrotation or chronic intermittent intestinal obstruction is a known entity which was noticed in the infant of the present article. (12) laparotomy was preferred approach in many case reports but some surgeons ventured with laparoscopy for repair of defect for left mesocolic hernia. Authors performed laparoscopy in only one case but retrospectively accept laparoscopy is a better approach. Diagnostic laparoscopy and proceed would have reduced morbidity in few. (13)

Contrast enhanced CT scan of abdomen is gold standard to detect the small bowel clusters on right side with caecum position in relation to superior mesenteric vessels. (1) Sonography though feasible couldn't delineate the pathology in majority of cases. (14) On proceeding with laparotomy, ischemic segment of ileum was found in young patients who required resection \& anastomosis. (15) In this series of six cases, we had to resect and anastomose ileal segment in two patients. Post operative outcome was good in all cases except infant who expired. Post-operative sepsis following malrotation surgery in infant after achieving bowel motility was unexpected. Malabsorption and FTT due to antenatal midgut volvulus with mesocolic hernia might had contributed to multi-organ failure (16).

\section{CONCLUSION}

Authors had attempted to describe a rare variety of internal hernia in children retrospectively collected from hospital records. Laparoscopic approach is recommended for cases presenting with mild symptoms. Left sided mesocolic hernia is more common \& right mesocolic hernia is easier to correct surgically. Care should be taken while explaining patients preoperatively as ischemic ileal segment might prolong morbidity in some cases.

\section{REFERENCES}

Martin, L.C., Merkle, E.M. and Thompson, W.M. 2006. Review of internal hernias: radiographic and clinical findings. AJR Am. J. Roentgenol., 186(3): 703-17.

Willwerth, B.M., Zollinger, R.M. Jr, and Izant, R.J. Jr. 1974. Congenital mesocolic (paraduodenal) hernia. Embryologic basis of repair. Am. J. Surg., 128(3): 358-61.
Chamely, E. and Antao, B. 2020. Congenital Middle Mesocolic Hernia: A Rare Cause of Neonatal Intestinal Obstruction. J. Neonatal Surg. [nternet], 5(4): 58.

Ghahremani, G.G. 1984. Internal abdominal hernias. Surg Clin North Am., 64: 393-406.2.

Newsom, B.D. and Kukora, J.S. 1986. Congenital and acquired internal hernias: unusual causes of small bowel occlusion. Am J Surg., 152: 279-85.

Abukhalaf, S.A., Mustafa, A., Elqadi, M.N., Al Hammouri, A., Abuzaina, K.N.M., Abukarsh, R., Ghazzawi, I., Hassan, S. and Novotny, N.M. 2019. Paraduodenal hernias in children: Etiology, treatment, and outcomes of a rare but real cause of bowel obstruction. Int. J. Surg. Case Rep., 64: 105-108.

Janin, Y., Stone, A.M. and Wise, L. 1980. Mesenteric hernia. Surg Gynaecol Obstet, 150:747-5.

Huang, Y.M., Chou, A.S., Wu, Y.K., Wu, C.C., Lee, M.C., Chen, H.T. and Chang, Y.J. 2005. Left paraduodenal hernia presenting as recurrent small bowel obstruction. World J. Gastroenterol., 11(41): 6557-9.

Munir, A., Saleem, S.M. and Hussain, S. 2004. Paraduodenal hernia--a case report. J. Pak. Med. Assoc., 54(3): 162-3.

Shadhu, K., Ramlagun, D. and Ping, X. 2018. Para-duodenal hernia: a report of five cases and review of literature. BMC Surg., 18(1): 32.

Balraj, A.T., Srinivas, S., Reddy, K.R., Reddy, M.G. and Inugala, A. 2018. Malrotation presenting beyond infancy: a clinical study. Int. Surg. J., 5: 3288-91.

Applegate, K.E., Anderson, J.M. and Klatte, E.C. 2006. Intestinal malrotation in children: a problem-solving approach to the upper gastrointestinal series. Radiographics, 26(5): 1485-500.

Hussein, M., Khreiss, M., Al-Helou, G., Alaeddine, M., Elias, E., Abi Saad, G.S. 2012. Laparoscopic repair of a left paraduodenal hernia presenting with acute bowel obstruction: report of a case. Surg. Laparosc Endosc Percutan Tech., 22(1): e28-30.

Blachar, A. and Federle, M.P. 2002. Internal hernia: an increasingly common cause of small bowel obstruction. Semin Ultrasound CT MR, 23(2): 174-83.

Tauro, L.F., Vijaya, G., D’Souza, C.R., Ramesh, H.C., Shetty, S.R., Hegde, B.R. and Deepak, J. 2007. Mesocolic hernia: an unusual internal hernia. Saudi J. Gastroenterol, 13(3): 141 3.

Raitio, A., Green, P.A., Fawkner-Corbett, D.W., Wilkinson, D.J. and Baillie, C.T. 2016. Malrotation: Age-Related Differences in Reoperation Rate. Eur. J. Pediatr. Surg., 26(1): 34-7. 